\title{
A Study on the English Language Competency of the First Year Tamil Medium Engineering Students
}

\author{
S. Subha ${ }^{1}$, K. Abirami i ${ }^{2}$, M. Ambikavathy ${ }^{3}$, D. Eswaran ${ }^{4}$ and K. Manikandan ${ }^{4}$ \\ 'Department of Science and Humanities, M Kumarasamy College of Engineering, Thalavapalayam - \\ 639113, Tamil Nadu, India; subhaprasath2012@gmail.com \\ ${ }^{2}$ Department of English, Srinivasa Ramanujan Centre, SASTRA deemed University, Kumbakonam - \\ 612001, Tamil Nadu, India; abirami@src.sastra.edu \\ ${ }^{3}$ Department of English, Periyar University College of Arts and Science, Dharmapuri - \\ 636905, Tamil Nadu, India; visit.ambika@gmail.com \\ ${ }^{4}$ Department of English, Madurai Kamaraj University Constituent College, Sattur - 626203, \\ Tamil Nadu, India; joeswar1984@gmail.com, manikprofessor@gmail.com
}

\begin{abstract}
Objectives: The study aims to develop the language (communicative) competency of the selected students with the help of activity based language learning strategy. Methods/Statistical Analysis: A sample of 75 students from engineering stream, who had Tamil as their medium of instruction in higher secondary education was taken for the study. A pre-test has been done to identify the issues and the affective factors of language competency among the target population. Tasks are then designed in order to improve the language competency of the selected students based on their needs and also the tasks are designed in order to decrease the level of the affective factors. After the implementation of the tasks, a post-test questionnaire is administered and the effect of the tasks on improving the language competency of the entry level Tamil medium engineering students is analyzed. Findings: Based on the performance of the learners in the activities provided such as mini presentation and group discussion, it has been found that the activity based teaching is appropriate for the target learners. As the learners are from Tamil medium they face challenges in using the second language. The researcher found that the level of competency of the learners is not satisfactory. The researchers have designed that activities based on the competency level of the learners in the entry-test. Finally, the researcher has found that the activity based teaching has enhanced the performance of the level of the learners in the exit-test. Application/Improvements: The study can be applied to improve English language skills of students of any other regional language.
\end{abstract}

Keywords: language learning, competency, engineering students, first year, entry-test, exit- test

\section{Introduction}

The higher secondary exam on English remains a challenge for many regional language students at their board examination. English language teachers have the responsibility of assisting the learners in enriching their communicative abilities ${ }^{1,2}$ Once they complete the exam they think they are free from language tensions on writing and speaking, where listening and reading have a minor role to play in day - to- day life. But the case is different. They do not realize that they studied language as a subject at their school whereas in colleges, at tertiary level, language takes many forms of realia. Scoring mark is not the target but to achieve success in productive skills and communication is the goal. Even though many Tamil medium students join Anna University Engineering

${ }^{*}$ Author for correspondence 
courses, most of them struggle to understand and get through the exams without piling arrears. There were no courses available for the learners who enter the engineering colleges to bridge their gap between school and college education which makes the learning more complex. The present scenario professional engineers certainly need effective and impressive communication skills. It is in this background; this study has been undertaken to enhance the language competency of the Tamil medium engineering students. In ${ }^{3,4}$ noted errors function as important links for teachers and students. She says that currently language learning process is considered as a creative construction process. Errors are a vital source of information in the language teaching process since they provide information about the language learning by indicating the learner's innate strategies of learning, she added.

\section{Method of Study}

The present study on engineering students who are from regional medium stresses that language is more important than they think of its role and have made an analysis through questionnaire method. ${ }^{3}$ Engineers need to be able to communicate their thoughts, ideas and plans to many other specialists in many different fields. Therefore, communication skills are crucial for engineering students to ensure a secure placement and a comfortable life. The conducted activities are done through Task Based teaching method. An entry- test and exit- test was also conducted.

A sample of 75 students from engineering stream, who had Tamil as their medium of instruction in higher secondary education was taken for the study. An Entry-test questionnaire had been administered to find the factors affecting the language competency of the learners. Tasks were then designed to reduce the level of affective factors. An Exit test questionnaire was given to evaluate the impact of activities provided to identify their communication competency of the target students. The tools used are Digital Language Lab and Language Verbal Test. Data was analyzed with the help of ' $'$ ''-test.

\subsection{Entry-Test}

An Entry test was designed with a view of assessing the level of language competency and the problems. The general aim of the entry test was prescribed as testing the language competency of the learners. To assess their standard as ESL learners, the following specific objectives of entry test were taken into account:

- To observe how far the learners are focused in listening to English

- To observe the learner's oral communication level

- To recognize the repeated flaws in their English language speaking and writing.

- To examine their level of competency in writing.

- To evaluate the communicative ability of the learners.

- To interpret the unique language needs of the learners.

- The entry test had the following points in the forms of questioners focusing at achieving the afore-mentioned objectives:

- The learners were instructed to converse among the peers on a given role-play activity.

- To verify their writing, questions were provided requiring for their relevant answers.

- To investigate their level and their challenges in communication, six questions were posed. With the help this task, their verbal proficiency was evaluated and the least proficient skills were identified.

- This task was designed to induce the learners to provide descriptive answers.

\subsubsection{Factors that Affect the Learner's Competency}

From the Entry-Test Questionnaire and from the previous studies, following are the factors that are identified to affect the language competency of the entry level Tamil medium students:

1. Social and financial status, family background and personality traits were identified as significant factors affecting the language competency of the students selected for the research.

2. Learning methods such as habits, approaches, styles and effectiveness of the learners greatly affected the level of competency of the learners.

3. The performance of individuals pursuing Engineering course is predominantly influenced by the medium of study at school. 
4. Learners' interest in classroom activities, communication apprehension, their confidence level, views about the language classroom, instructor and the curriculum.

5. Response from the felicitator plays a significant role in enabling effective learning for effective learning. It can be observed as a "consequence" of the learner's performance that the felicitator can monitor.

6. Quick expressions, unaccustomed pronunciation and differing speed of delivering the content by the instructor.

\subsubsection{Planning Activities}

To minimize the identified factors affecting communication the following activities were planned and executed.

1. Digitalized Communication Lab:

1.1 Listen and Reproduce: Learners will be allowed to listen to a short passage spoken by a native speaker and are asked to reproduce it.

1.2 Oral Communication practice:

Learners were asked to read an article or a magazine. The felicitator will instruct the learners to interpret the given text and discuss among the peers. The felicitator would observe the learner's performance in the activity.

\subsection{Group Discussion and mini presentation:}

The learners would be asked to share their views on the topic provided and the peers are instructed to work in groups or individually based on their interest. Finally, the learners were allowed to prepare a report on their activity.

\subsection{Exit- Test}

After the execution of the planned activities an evaluation was done to identify the progress of their communicative competence. The questioners used were different for each learner to avoid repetition of responses the main focus of the exit test is as follows:

- To analyze the feasibility of participation among the learners.

- To ascertain the extent of involvement and readiness expressed by the learners in becoming more competent.

\section{Results and Discussion}

The learners, who felt shy during their entry test felt at ease after the execution of activity based teaching focusing on four language skills. Peer learning helps the learners to get more involved in the activities. Activities conducted using Digitalized Language Lab promotes a better leaning environment, thereby providing opportunities for every learner to exhibit their language ability and in becoming more competent. In argues that desire to communicate and sensitivity to the out- group are its two fundamental types, the presence of which can considerably influence the level of success in language learning.

\section{Conclusion}

The researcher identified that the learners must avoid mother tongue influence in their communication through constant exposure to native language user such as listening to native speakers and having conversation. The level of anxiety among the Tamil medium learners can be reduced through informal classroom activities like selfintroduction, introducing others, product launch, etc... Digitalized Language Lab provides the ample resources thereby assisting every individual to develop their level of competency in communication.

\section{References}

1. Chandrakanthi S, Ananthasayanam. Socio-pedagogical factors affecting language skills among engineering college students. Dissertation; 2003. p. 157.

2. Kumbhar PAA. Study of the impact of the medium of instruction at school level on the performance of individuals pursuing engineering and medical courses. Dissertation; 2003.

3. Nida EA. Motivation in second language learning. Language Learning. 1956; 7(3-4):11-16. https://doi. org/10.1111/j.1467-1770.1956.tb01198.x

4. Siddique R. Learning from Learners: Constructing Evaluation and Feedback Methodology from Error Analysis. East West Journal. 2007; 1:19-2. 